\title{
Orbus hercynius gen. nov., sp. nov., isolated from faeces of wild boar, is most closely related to members of the orders 'Enterobacteriales' and Pasteurellales
}

Correspondence Gottfried Wilharm wilharmg@rki.de

\author{
Maria Volkmann, ${ }^{1}$ Evelyn Skiebe, ${ }^{1}$ Tobias Kerrinnes, ${ }^{1}$ Franziska Faber, ${ }^{1}$ \\ Daniela Lepka, ${ }^{1}$ Yvonne Pfeifer, ${ }^{1}$ Gudrun Holland, ${ }^{2}$ Norbert Bannert ${ }^{2}$ \\ and Gottfried Wilharm ${ }^{1}$
}

\author{
${ }^{1}$ Robert Koch-Institute, Wernigerode Branch, Burgstr. 37, D-38855 Wernigerode, Germany \\ ${ }^{2}$ Robert Koch-Institute, ZBS 4, Nordufer 20, D-13353 Berlin, Germany
}

\begin{abstract}
A novel gammaproteobacterium, strain $\mathrm{CN}^{\top}$, was isolated from the faeces of wild boar. Strain $\mathrm{CN}^{\top}{ }^{\top}$ was facultatively anaerobic and appeared coccoid or rod-shaped. The partial $16 \mathrm{~S}$ rRNA gene sequence determined for strain $\mathrm{CN}^{\top}{ }^{\top}$ suggested a distant relationship with members of the orders 'Enterobacteriales' and Pasteurellales. The gene sequence showed highest similarity (90.3\%) with Obesumbacterium proteus DSM $2777^{\top}$, a member of the family

Enterobacteriaceae. The closest relatives outside the order 'Enterobacteriales' according to $16 \mathrm{~S}$ rRNA gene sequence analysis were members of the order Pasteurellales with $88.7 \%$ similarity (Mannheimia haemolytica NCTC $9380^{\top}$ and Actinobacillus lignieresii NCTC $4189^{\top}$ ). In contrast to most members of the order 'Enterobacteriales', strain $\mathrm{CN}^{\top}{ }^{\top}$ was oxidase-positive. The pattern of fatty acids, in particular the high relative abundance of $\mathrm{C}_{18: 1} \omega 7 \mathrm{c}(38.5 \%)$, was clearly distinct from the conserved pattern found for members of the order Pasteurellales. EcoRI ribotyping of strain $\mathrm{CN}^{\top}$ yielded no significant similarity to existing database entries. The major ubiquinone of strain $\mathrm{CN}^{\top}{ }^{\top}$ was $\mathrm{Q}-8$. The DNA $\mathrm{G}+\mathrm{C}$ content was $36.4 \mathrm{~mol} \%$. Strain $\mathrm{CN}^{\top}$ hosted a phage and secreted considerable amounts of three proteins into the culture supernatant. A spontaneous mutant of strain $\mathrm{CN}^{\top}{ }^{\top}$ was isolated which formed long filaments. Microscopic studies revealed the presence of a capsule that the mutant strain was unable to partition after cell division. Strain $\mathrm{CN}^{\top}$ thus represents a novel species within a new genus, for which the name Orbus hercynius gen. nov., sp. nov. is proposed. The type strain of the type species is $\mathrm{CN}^{\top}{ }^{\top}$ (=DSM $22228^{\top}=$ CCUG $57622^{\top}$ ). Classification of the novel species to the family and order level will require further investigations.
\end{abstract}

In search of Yersinia enterocolitica, which is frequently isolated from swine, samples of wild boar faeces were collected from the Halberstadt Zoo, Germany $\left(51^{\circ} 53^{\prime} 45^{\prime \prime} \mathrm{N}, 11^{\circ} 2^{\prime} 48^{\prime \prime} \mathrm{E}\right)$. Fresh faecal samples collected from the ground were suspended in sterile water and suspensions were plated on cefsulodin-irgasan-novobiocin (CIN) agar plates (Schiemann, 1979). After incubation at $27{ }^{\circ} \mathrm{C}$ for $40 \mathrm{~h}$, Yersinia-like colonies with a 'bulls-eye'

Abbreviations: SEM, scanning electron microscopy; TEM, transmission electron microscopy.

The GenBank/EMBL/DDBJ accession number for the 16S rRNA gene sequence of strain $\mathrm{CN}^{\top}$ is FJ612598.

Supplementary figures showing the morphology, growth and motility of strain $\mathrm{CN}^{\top}$ and the SDS-PAGE analysis are available with the online version of this paper. appearance were subjected to PCR using $16 \mathrm{~S}$ rRNA gene primers specific for European bio-serotypes of $Y$. enterocolitica (Trebesius et al., 1998). For images of the colonies on CIN plates, see Supplementary Fig. S1 in IJSEM Online. Since no PCR-product was obtained from the Yersinia-like colonies derived from one of the faecal samples, an approximately $1500 \mathrm{bp}$ fragment of the 16S rRNA gene of the representative isolate, strain $\mathrm{CN} 3^{\mathrm{T}}$, was amplified using primers designed for members of the family Enterobacteriaceae and relatives (primers $\mathrm{fD} 2$ and $\mathrm{rP} 1$ according to Weisburg et al., 1991) and was subsequently sequenced. To confirm the DNA sequencing results, the Identification Service of the Deutsche Sammlung von Mikroorganismen und Zellkulturen GmbH (Dr Cathrin Spröer, DSMZ) was commissioned to perform a $16 \mathrm{~S}$ rRNA gene sequence analysis on strain $\mathrm{CN}^{\mathrm{T}}$. The partial $16 \mathrm{~S}$ 
rRNA gene sequence determined, encompassing 1522 bp of strain $\mathrm{CN}^{\mathrm{T}}$, showed the highest sequence similarity, $90.3 \%$, with Obesumbacterium proteus DSM $2777^{\mathrm{T}}$, a member of the family Enterobacteriaceae. Many other members of the family Enterobacteriaceae, as well as representatives of the genera Salmonella, Shigella, Klebsiella, Yersinia, Enterobacter and others, showed gene sequence similarities in the range 89 to $90 \%$. The closest relatives outside the order 'Enterobacteriales', according to $16 \mathrm{~S}$ rRNA gene sequence analysis, were members of the order Pasteurellales with $88.7 \%$ similarity (Mannheimia haemolytica NCTC $9380^{\mathrm{T}}$ and Actinobacillus lignieresii NCTC $4189^{\mathrm{T}}$ ). To illustrate the phylogenetic relationships of strain $\mathrm{CN}^{\mathrm{T}}, \mathrm{a}$ neighbour-joining tree is presented in Fig. 1.

From the 16S rRNA gene sequence determined for $\mathrm{CN}^{\mathrm{T}}$, primers were constructed for the amplification of a $16 \mathrm{~S}$ rRNA gene fragment. The sequence of the selected forward primer 5' 5 -TATGGAGTGTGGGGGCATGAC-3' ${ }^{\prime}\left(\mathrm{CN}^{\mathrm{T}}{ }^{-}\right.$ ident-for) was unique among all nucleotide database entries. Only a few database entries were found with identical 3' ends so that high stringency of the PCR conditions allowed the specificity of the PCR to be controlled. Reverse primer 5'-GTCCGCTCCAGTTCGCACC-3' (CN3 $^{\mathrm{T}}$-identrev) was less specific, but the sequence was found in only a very few other bacteria. A PCR protocol using crude bacterial lysates and with total isolated DNA from faeces (isolated with QIAamp DNA Stool Mini kit from Qiagen according to the manufacturer's instructions) was established which yielded a specific product of 457 bp but never yielded unspecific products. PCR conditions were 30 cycles with $30 \mathrm{~s}$ at $94{ }^{\circ} \mathrm{C}, 30 \mathrm{~s}$ at $58{ }^{\circ} \mathrm{C}, 30 \mathrm{~s}$ at $72{ }^{\circ} \mathrm{C}$ after an initial denaturation step at $94{ }^{\circ} \mathrm{C}$ for $2 \mathrm{~min}$. By applying this PCR protocol, more than 20 faecal samples from wild boar were screened for the presence of relatives of strain $\mathrm{CN} 3^{\mathrm{T}}$ but the strain was not detected in any other sample. Further parallel trials to isolate strains related to $\mathrm{CN} 3^{\mathrm{T}}$ from the same samples by applying culture techniques also failed.

\section{Phenotypic and cultural characteristics}

The cell morphology of strain $\mathrm{CN} 3^{\mathrm{T}}$ was examined by scanning and transmission electron microscopy (SEM, TEM; Fig. 2). Strain $\mathrm{CN} 3^{\mathrm{T}}$ appeared coccoid to rod-shaped with typical dimensions of $1-1.5 \times 0.8 \mu \mathrm{m}$ (Fig. 2a). TEM further revealed that strain $\mathrm{CN} 3^{\mathrm{T}}$ hosted a phage that was morphologically related to the Myoviridae (Fig. 2b). Since no flagella and no swimming motility could be observed, the novel strain was tested on semi-solid media for surfaceassociated forms of motility (see Supplementary Fig. S2 in IJSEM Online). Strain $\mathrm{CN}^{\mathrm{T}}$ was inoculated on $0.3 \%$ agar plates containing $2 \times \mathrm{YT}$ broth $\left(16 \mathrm{~g} \mathrm{l}^{-1}\right.$ tryptone, $10 \mathrm{~g} \mathrm{l}^{-1}$ yeast extract, $5 \mathrm{~g} \mathrm{l}^{-1} \mathrm{NaCl}$ ) by puncturing the agar and was then incubated for 7 days at $27{ }^{\circ} \mathrm{C}$. Drying was prevented by wrapping with Parafilm. Strain $\mathrm{CN} 3^{\mathrm{T}}$ was found to move slowly on the agar surface with a variable morphological appearance. Movement of strain $\mathrm{CN} 3^{\mathrm{T}}$ could also be observed at the boundary between the bottom of the agar layer and the polystyrene Petri-dish (referred to here as the 'interphase'; see Supplementary Fig. $\mathrm{S} 2$ ). To visualize the biofilm at the interphase, the agar

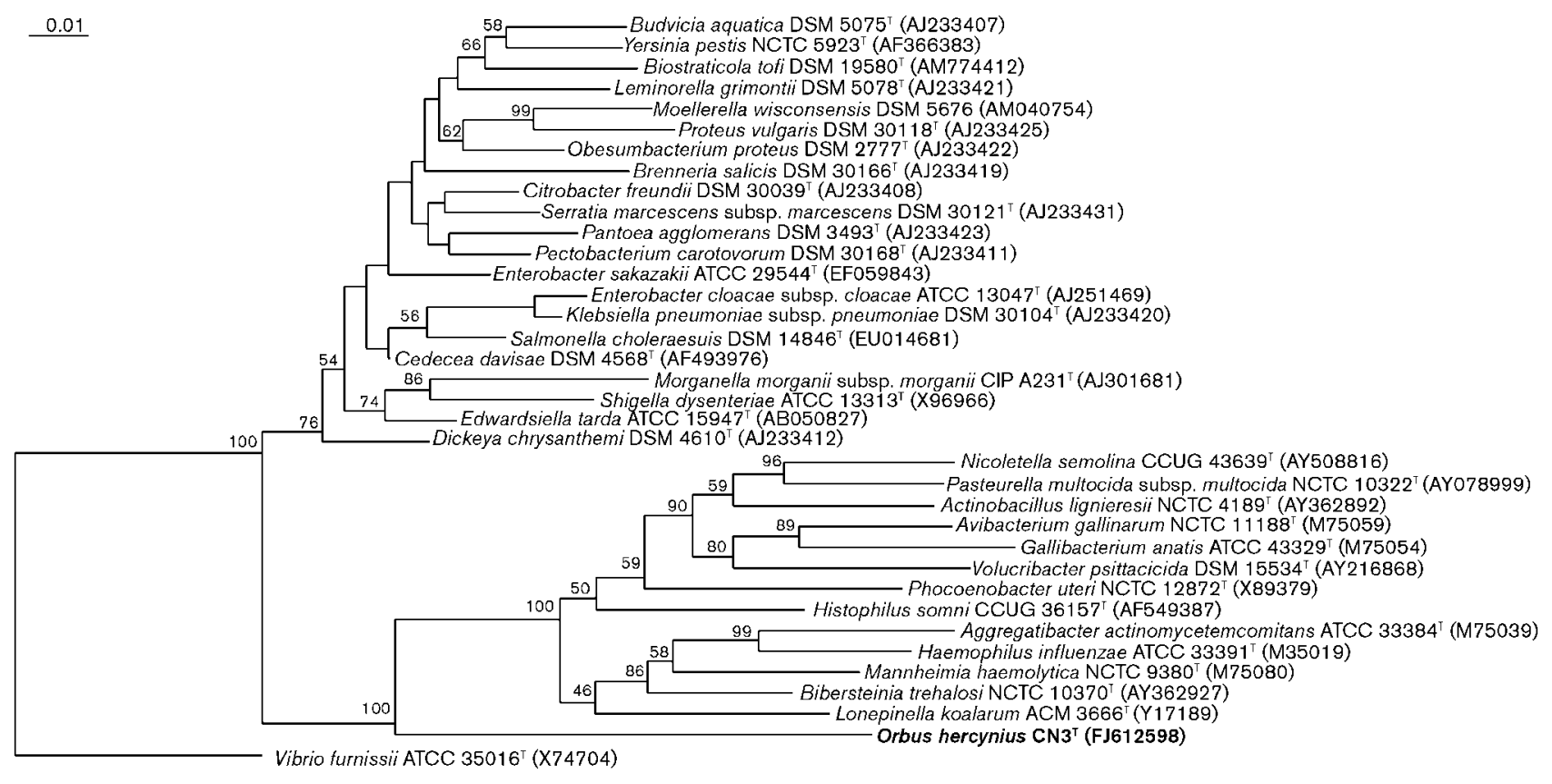

Fig. 1. Neighbour-joining phylogenetic reconstruction from almost complete $16 \mathrm{~S}$ rRNA gene sequences using the ARB package (Pruesse et al., 2007) and the correction of Jukes \& Cantor (1969). The root of the tree was determined by including the $16 S$ rRNA gene sequence of Vibrio furnissii in the analysis. Bar, 1 nt substitution per 100 nt. 

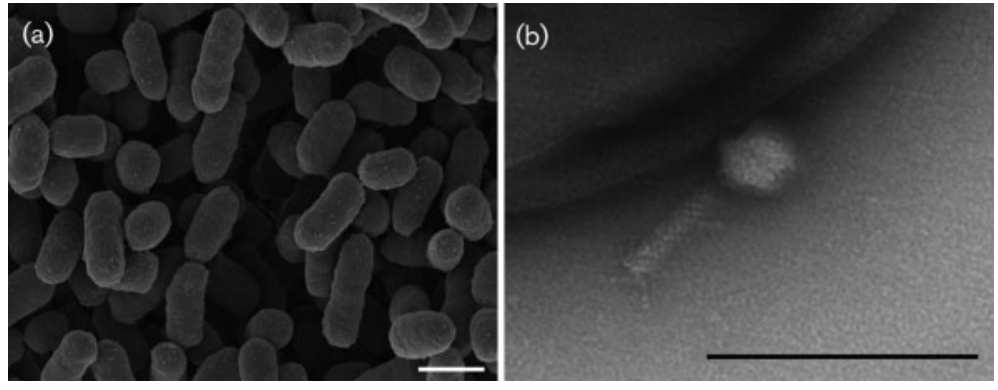

Fig. 2. (a) SEM of cells of strain $\mathrm{CN}^{\top}$ after cultivation on $2 \times \mathrm{YT}$ agar for $40 \mathrm{~h}$ at $27^{\circ} \mathrm{C}$. (b) TEM (negative staining) of a phage of strain $\mathrm{CN}^{\top}$. Bars, $1 \mu \mathrm{m}(\mathrm{a}), 200 \mathrm{~nm}(\mathrm{~b})$. layer was removed and bacteria attached to the polystyrene surface were stained with Coomassie blue (see Supplementary Fig. S2). One surface-associated form of motility, termed twitching motility, has been associated with polarly localized type IV pili in several bacteria (Mattick, 2002). However, TEM and SEM examinations did not point to such a mechanism for strain $\mathrm{CN} 3^{\mathrm{T}}$, leaving open the mechanism behind this form of motility.

When inspecting motility by light microscopy, a spontaneous filamentous mutant was identified on semi-solid agar $(0.3 \%)$ and characterized by light and electron microscopy (see Supplementary Fig. S3). Filaments of at least $50 \mu \mathrm{m}$ in length were observed which appeared to be coated by a capsule-like sheath. Bacteria had escaped from some filament segments, leaving behind the empty sheath (see Supplementary Fig. S3), which collapsed during sample preparation for SEM resulting in a beading phenotype (see Supplementary Fig. S2). Interestingly, some of the beads had a spore-like appearance with a diameter exceeding that of the filament. It remains to be determined whether these beads are of biological relevance or whether they represent artefacts.

Strain $\mathrm{CN}^{\mathrm{T}}$ grew well in $2 \times \mathrm{YT}$ broth at $27{ }^{\circ} \mathrm{C}$; growth was suboptimal in Luria-Bertani (Alpha Biosciences) and brain heart-infusion (Becton Dickinson) media. Besides growth on CIN agar plates (Supplementary Fig. S1), strain $\mathrm{CN}^{\mathrm{T}}$ grew on bile-chrysoidine-glycerol agar (GCG agar, Heipha Diagnostika; Ziesché et al., 1985) forming small grey colonies after incubation for $48 \mathrm{~h}$ at $27^{\circ} \mathrm{C}$. The optimum temperature for growth of strain $\mathrm{CN}^{\mathrm{T}}$ was tested in $2 \times$ YT broth, both under aerobic and anaerobic conditions (paraffin overlay) in the range 16 to $40{ }^{\circ} \mathrm{C}$ (see Supplementary Fig. S4). After incubation for $18 \mathrm{~h}$, a broad temperature optimum was found between 20 and $30{ }^{\circ} \mathrm{C}$ with a sharp drop in growth above $36{ }^{\circ} \mathrm{C}$ and below $20{ }^{\circ} \mathrm{C}$, both under aerobic and anaerobic conditions. However, significant growth was also observed at $4{ }^{\circ} \mathrm{C}$ (incubation in $2 \times$ YT broth for 7 days without shaking).

The $\mathrm{pH}$-dependent growth range was tested in buffered $2 \times$ YT broth at $22{ }^{\circ} \mathrm{C}$ at between $\mathrm{pH} 4$ and 10 . Significant growth of strain $\mathrm{CN}^{\mathrm{T}}$ was observed between $\mathrm{pH} 6$ and $\mathrm{pH} 8$ with an optimum around $\mathrm{pH} 7.5$.

In the API $20 \mathrm{NE}$ test system, strain $\mathrm{CN}^{\mathrm{T}}$ showed nitrate reduction, glucose fermentation, urease activity and aesculin hydrolysis after incubation at $30{ }^{\circ} \mathrm{C}$ for $48 \mathrm{~h}$. No arginine dihydrolase activity, indole production, gelatin hydrolysis or $\beta$-galactosidase activity was observed. Assimilation of D-glucose, L-arabinose, D-mannose, D-mannitol, $\mathrm{N}$-acetylglucosamine, maltose, gluconate, capric acid, adipic acid, malic acid, citrate or phenylacetic acid were all negative for strain $\mathrm{CN}^{\mathrm{T}}$ as shown with the API $20 \mathrm{NE}$ system.

\section{Chemotaxonomic properties}

Analysis of respiratory quinones was carried out by $\mathrm{Dr}$ Brian Tindall of the DSMZ Identification Service, Germany. The major ubiquinone of strain $\mathrm{CN} 3^{\mathrm{T}}$ was Q-8. Since Q-8 is also the major ubiquinone of some members of the family Pasteurellaceae, as well as of some members of the family Enterobacteriaceae and other gammaproteobacteria, this result did not allow further classification of strain $\mathrm{CN}^{\mathrm{T}}$.

Ribotyping was performed with the Qualicon RiboPrinter system by Dr Peter Schneider of the DSMZ Identification Service. The EcoRI riboPrint pattern showed no significant similarity $(>0.85)$ to the entries in the DuPont identification library or to entries in the internal DSMZ database.

The DNA base composition $\left(\mathrm{G}+\mathrm{C}\right.$ content) of strain $\mathrm{CN}^{\mathrm{T}}$ was determined by Dr Peter Schumann of the DSMZ Identification Service, following the procedure described by Mesbah et al. (1989). The $\mathrm{G}+\mathrm{C}$ content of strain $\mathrm{CN} 3^{\mathrm{T}}$ was $36.4 \mathrm{~mol} \%$ (two independent determinations). For comparison, the DNA $\mathrm{G}+\mathrm{C}$ content of members of the family Enterobacteriaceae is typically in the range 45 to $55 \%$, with the exception of Proteus mirabilis (38.9\%) (http://www.ncbi. nlm.nih.gov/genomes/lproks.cgi). Members of the family Pasteurellaceae typically have DNA G+C contents of around $40 \%$ (Actinobacillus 41-44\%, Haemophilus 37$40 \%$, Mannheimia $43 \%$ ) (http://www.ncbi.nlm.nih.gov/ genomes/lproks.cgi).

No plasmids could be identified using standard plasmid purification protocols.

Fatty acids were extracted and analysed by the Identification Service of the DSMZ according to the standard protocol of the Microbial Identification System (MIDI Microbial ID Inc.) by using the TSB40 method. The major fatty acids determined for strain $\mathrm{CN}^{\mathrm{T}}$ were $\mathrm{C}_{18: 1} \omega 7 c$ 
(38.45\%) and $\mathrm{C}_{16: 0}(33.73 \%)$ (Table 1). It is important to note that fatty acid profiles are highly conserved among members of the family Pasteurellaceae with $\mathrm{C}_{18: 1} \omega 7 c$ not being a regular constituent (Mutters et al., 1993; Christensen et al., 2007).

\section{Strain $\mathrm{CN}^{\mathrm{T}}{ }^{\mathrm{d}}$ does not interact with HeLa cells}

HeLa cells were cultured in EMEM medium (Cell Concepts) supplemented with $1 \%$ non-essential amino acids, $2 \mathrm{mM}$ glutamine and $5 \%$ heat-inactivated fetal calf serum (FCS). For infection experiments, eukaryotic cells were cultivated in SonicSeal slide wells (Nunc). After overnight culture of strain $\mathrm{CN}^{\mathrm{T}}$ in $2 \times \mathrm{YT}$ or on $2 \times \mathrm{YT}$ agar plates $\left(27^{\circ} \mathrm{C}\right)$, HeLa cells were infected with strain $\mathrm{CN}^{\mathrm{T}}$ (m.o.i. 50) and infected cultures were further incubated for $3 \mathrm{~h}$ at $37{ }^{\circ} \mathrm{C}$ in the presence of $5 \% \mathrm{CO}_{2}$. The wells were then washed five times with PBS $\left(8 \mathrm{~g} \mathrm{l}^{-1}\right.$ $\mathrm{NaCl}, \quad 1.15 \mathrm{~g} \mathrm{l}^{-1} \quad \mathrm{Na}_{2} \mathrm{HPO}_{4}, \quad 0.2 \mathrm{~g} \mathrm{l}^{-1} \mathrm{KCl}, \quad 0.2 \mathrm{~g} \mathrm{l}^{-1}$ $\mathrm{KH}_{2} \mathrm{PO}_{4}$ ) and cells were fixed in methanol for $5 \mathrm{~min}$, stained with Accustain modified Giemsa stain (Sigma) and examined under a light microscope. Neither significant adherence of strain $\mathrm{CN} 3^{\mathrm{T}}$ to HeLa cells nor any cytopathic effects could be observed. Given the poor growth of strain $\mathrm{CN} 3{ }^{\mathrm{T}}$ at $37{ }^{\circ} \mathrm{C}$ and the lack of evidence for interaction with HeLa cells, we do not expect the novel strain to be a potential pathogen of endotherms. Therefore, isolation of this novel strain from wild boar faeces was probably due to accidental intestinal passage after uptake from soil or feed or due to the contamination of the faecal samples that were collected from the ground. This observation was in agreement with our unsuccessful efforts to isolate organisms related to strain $\mathrm{CN}^{\mathrm{T}}$ from any other faecal sample.

\section{Secreted proteins}

We also analysed whether strain $\mathrm{CN} 3^{\mathrm{T}}$ secreted proteins into the culture supernatant. Single colonies were

Table 1. Fatty acid composition of strain $\mathrm{CN}^{\top}$

\begin{tabular}{|lc|}
\hline Fatty acid & Proportion (\%) \\
\hline $\mathrm{C}_{10: 0}$ & 0.08 \\
$\mathrm{C}_{12: 0}$ & 0.16 \\
$\mathrm{C}_{14: 0}$ & 6.88 \\
Unknown 14.502 & 0.10 \\
$\mathrm{C}_{16: 1} \omega 5 c$ & 0.17 \\
$\mathrm{C}_{16: 0}$ & 33.73 \\
$\mathrm{C}_{18: 1} \omega 7 c$ & 38.45 \\
$\mathrm{C}_{18: 0}$ & 0.35 \\
Summed features & \\
2 & 9.37 \\
3 & 10.70 \\
\hline
\end{tabular}

${ }^{*}$ Summed feature 2 comprises iso- $\mathrm{C}_{16: 1} \mathrm{I}, \mathrm{C}_{14: 0} 3-\mathrm{OH}$ and/or $\mathrm{C}_{12: 0}$ aldehyde; summed feature 3 comprises $C_{16: 1} \omega 7 c$ and/or iso- $C_{15: 0}$ 2-OH. suspended in $3 \mathrm{ml} 2 \times \mathrm{YT}$ broth and cultured for $24 \mathrm{~h}$ at $27{ }^{\circ} \mathrm{C}$ under aerobic and anaerobic conditions, respectively, as described above. Fractions of $2 \mathrm{ml}$ were then centrifuged for $10 \mathrm{~min}$ at $10000 \mathrm{~g}$ to pellet the bacteria. A $1.7 \mathrm{ml}$ sample of cleared supernatant was then transferred to a new tube for the precipitation of proteins with $200 \mu \mathrm{l}$ trichloroacetic acid. After $1 \mathrm{~h}$ incubation on ice, samples were centrifuged for $30 \mathrm{~min}$ at $4{ }^{\circ} \mathrm{C}(14000 \mathrm{~g})$ and the supernatants were discarded after centrifugation. The pellets were washed twice with ice-cold acetone and subsequently air-dried. Pellets were dissolved in $30 \mu \mathrm{l}$ SDS-PAGE loading buffer (Trček et al., 2002) and $10 \mu \mathrm{l}$ samples were subjected to SDS-PAGE analysis (Laemmli, 1970). Strain $\mathrm{CN}^{\mathrm{T}}$ secreted three proteins with approximate molecular masses of 55, 37 and $23 \mathrm{kDa}$ at considerable amounts (each at approx. $0.5-2 \mathrm{mg} \mathrm{l}^{-1}$ ) irrespective of the presence of oxygen (see Supplementary Fig. S5 in IJSEM Online).

\section{Resistance to antibiotics}

In a standard microbroth dilution assay conducted according to established protocols (NCCLS, 1997, 1999), resistance to the following commonly used antibiotics belonging to different antibiotic classes was determined: ampicillin, mezlocillin, mezlocillin-sulbactam, cefotiam, cefotaxime, ceftazidime, cefoxitin, gentamicin, kanamycin, amikacin, streptomycin, nalidixic acid, chloramphenicol, oxytetracycline, ciprofloxacin, sulfameracin, sulfameracintrimethoprim. Strain $\mathrm{CN}^{\mathrm{T}}$ was sensitive to all antibiotics with the exception of ampicillin and cefoxitin, for which minimal inhibitory concentrations of 8 and $2-16 \mathrm{mg} \mathrm{ml}^{-1}$, respectively, were determined, reflecting intermediate resistance.

\section{Classification}

Strain $\mathrm{CN}^{\mathrm{T}}$ is considered to represent a novel species and genus within the class Gammaproteobacteria. This proposal is substantiated by its isolated phylogenetic position according to $16 \mathrm{~S}$ rRNA gene sequence analysis, the presence of the oxidase reaction in contrast to most members of the order 'Enterobacteriales', the high relative abundance of fatty acid $\mathrm{C}_{18: 1} \omega 7 \mathrm{c}$ in contrast to the order Pasteurellales, and the distinct ribotype pattern. The name Orbus hercynius gen. nov., sp. nov. is proposed. Determination of the exact taxonomic standing within the class Gammaproteobacteria will require further studies and probably the description of a novel family and order.

\section{Description of Orbus gen. nov.}

Orbus (Or'bus. L. masc. n. orbus orphan).

Mesophilic, psychrotolerant, chemoheterotrophic bacteria. Metabolism is aerobic and facultatively anaerobic. Major fatty acids are monounsaturated, even-numbered, straightchain $\mathrm{C}_{18} \quad\left(\mathrm{C}_{18: 1} \omega 7 c\right)$ and saturated, even-numbered, 
straight-chain $\mathrm{C}_{16}\left(\mathrm{C}_{16: 0}\right)$ fatty acids. Cells are coccoid or rod-shaped, Gram-negative, oxidase-positive and catalasepositive. The type species is Orbus hercynius.

\section{Description of Orbus hercynius sp. nov.}

Orbus hercynius (her.cy'ni.us. L. masc. adj. hercynius pertaining to Hercynia, N.L. name of the Harz Mountains, Germany).

Displays the following properties in addition to those described above for the genus. Cells are coccoid or short rods, $0.8 \mu \mathrm{m}$ wide, $1-1.5 \mu \mathrm{m}$ long and coated with a capsule-like sheath. Cells carry no flagella. Flagellaindependent motility alongside wet surfaces can be observed. Pigments are not produced. Colonies show a 'bulls-eye' appearance on CIN agar plates and grow up to 1-2 $\mathrm{mm}$ in diameter on CIN agar. Growth at $4-37{ }^{\circ} \mathrm{C}$ with optimal growth under aerobic conditions at $20-30{ }^{\circ} \mathrm{C}$. The API 20NE test system shows positive reactions for nitrate reduction, glucose fermentation, urease activity and aesculin hydrolysis. Arginine dihydrolase activity, indole production, gelatin hydrolysis and $\beta$-galactosidase activity are not observed. No assimilation of D-glucose, Larabinose, D-mannose, D-mannitol, $\mathrm{N}$-acetylglucosamine, maltose, gluconate, capric acid, adipic acid, malic acid, citrate or phenylacetic acid is shown with the API $20 \mathrm{NE}$ system. Major fatty acids are $\mathrm{C}_{18: 1} \omega 7 c, \mathrm{C}_{16: 0}$, summed feature 2 (iso- $\mathrm{C}_{16: 1} \mathrm{I}, \mathrm{C}_{14: 0} 3-\mathrm{OH}$ and/or $\mathrm{C}_{12: 0}$ aldehyde), summed feature $3\left(\mathrm{C}_{16: 1} \omega 7 c\right.$ and/or iso- $\left.\mathrm{C}_{15: 0} 2-\mathrm{OH}\right)$ and $\mathrm{C}_{14: 0}$. The major ubiquinone is Q-8.

The type strain, $\mathrm{CN}^{\mathrm{T}}\left(=\mathrm{DSM} 22228^{\mathrm{T}}=\mathrm{CCUG} 57622^{\mathrm{T}}\right)$, was isolated from faeces of wild boar collected at the Halberstadt Zoo, Germany. The G $+\mathrm{C}$ content of the DNA of the type strain is $36.4 \mathrm{~mol} \%$.

\section{Acknowledgements}

We are grateful to Michael Bussenius from the Zoo in Halberstadt for providing us with faecal samples from wild boar. We thank members of the DSMZ Identification Service team for data collection, Julia Hofmann for critical reading of this manuscript and Hans Georg Trüper for his advice on the nomenclature of the novel species. We appreciate DNA sequencing analyses performed by members of the DNA sequencing core facility at the Robert Koch-Institute in Berlin.

\section{References}

Christensen, H., Kuhnert, P., Busse, H. J., Frederiksen, W. C. \& Bisgaard, M. (2007). Proposed minimal standards for the description of genera, species and subspecies of the Pasteurellaceae. Int J Syst Evol Microbiol 57, 166-178.

Jukes, T. H. \& Cantor, C. R. (1969). Evolution of protein molecules. In Mammalian protein metabolism, pp. 21-132. Edited by H. N. Munro. New York: Academic press.

Laemmli, U. K. (1970). Cleavage of structural proteins during the assembly of the head of bacteriophage T4. Nature 227, 680-685.

Mattick, J. S. (2002). Type IV pili and twitching motility. Annu Rev Microbiol 56, 289-314.

Mesbah, M., Premachandran, U. \& Whitman, W. B. (1989). Precise measurement of the $\mathrm{G}+\mathrm{C}$ content of deoxyribonucleic acid by highperformance liquid chromatography. Int J Syst Bacteriol 39, 159167.

Mutters, R., Mouahid, M., Engelhard, E. \& Mannheim, W. (1993). Characterization of the family Pasteurellaceae on the basis of cellular lipids and carbohydrates. Zentralbl Bakteriol 279, 104-113.

NCCLS (1997). Methods for Dilution Antimicrobial Susceptibility Tests for Bacteria That Grow Aerobically. Approved standard M7-A4, 4th edn. Wayne, Pa: National Committee for Clinical Laboratory Standards.

NCCLS (1999). Performance Standards for Antimicrobial Susceptibility Testing. Ninth informational supplement, M100-S9. 1-1-1999. Wayne Pa: National Committee for Clinical Laboratory Standards.

Pruesse, E., Quast, C., Knittel, K., Fuchs, B. M., Ludwig, W., Peplies, J. \& Glöckner, F. O. (2007). SILVA: a comprehensive online resource for quality checked and aligned ribosomal RNA sequence data compatible with ARB. Nucleic Acids Res 35, 7188-7196.

Schiemann, D. A. (1979). Synthesis of a selective agar medium for Yersinia enterocolitica. Can J Microbiol 25, 1298-1304.

Trček, J., Wilharm, G., Jacobi, C. A. \& Heesemann, J. (2002). Yersinia enterocolitica YopQ: strain-dependent cytosolic accumulation and post-translational secretion. Microbiology 148, 1457-1465.

Trebesius, K., Harmsen, D., Rakin, A., Schmelz, J. \& Heesemann, J. (1998). Development of rRNA-targeted PCR and in situ hybridization with fluorescently labelled oligonucleotides for detection of Yersinia species. J Clin Microbiol 36, 2557-2564.

Weisburg, W. G., Barns, S. M., Pelletier, D. A. \& Lane, D. J. (1991). $16 \mathrm{~S}$ ribosomal DNA amplification for phylogenetic study. J Bacteriol 173, 697-703.

Ziesché, K., Reissbrodt, R. \& Rische, H. (1985). A bile-chrysoidineglycerol culture medium and its use in the diagnosis of gram-negative aerobic bacteria, especially Enterobacteriaceae. Z Gesamte Hyg 31, 516-518. 